\title{
EFFECT OF INTRACEREBROVENTRICULAR INJECTION OF InTERLEUKin-1-Beta on the Ventilatory Response to Hyperoxic HYPERCAPNIA
}

\author{
N. P. Aleksandrova, G. A. Danilova \\ Laboratory of Respiration Physiology, Pavlov Institute of Physiology, Russian Academy of Sciences, Saint-Petersburg, Russia
}

\begin{abstract}
Objective: Oxidative stress developed at several disease states and strenuous resistive breathing lead to the elevation of plasma and cerebral levels of proinflammatory cytokines. We hypothesized that the elevation of the cytokine level in body fluids would modulate breathing pattern and the ventilatory response to stimulation of central chemoreceptors by hypercapnia.

Material and methods: In experiments on anesthetized, tracheostomized, spontaneously breathing rats, the effects of intracerebroventricular injection of the human recombinant interleukin-1 $\beta$ (IL-1 $\beta$ ) (0.5 $\mu \mathrm{g} / \mathrm{rat}$ ) on breathing were studied.

Results: During resting breathing IL-1 $\beta$ evoked a significant increase in minute ventilation and in mean inspiratory flow. Furthermore, injection of IL-1 $\beta$ into the cerebral-spinal fluid decreases the responses of ventilation, tidal volume, and of mean inspiratory flow to carbon dioxide.

Conclusions: The elevation of a proinflammatory cytokine in cerebrospinal fluid intensifies ventilation by modulation of breathing pattern, but weakens the chemoreflex sensitivity to hypercapnia. The results suggest the participation of cytokines in the central control of breathing and in the mechanisms of central chemoreception.
\end{abstract}

Key words: cytokines, interleukin- $1 \beta$, respiration, central chemoreception, hypercapnic rebreathing

\section{INTRODUCTION}

It is known that chemoreceptor mechanisms play a major role in the control of respiration. Central chemoreceptive elements are chiefly responsible for pulmonary ventilation during hypercapnia. A rapid increase in pulmonary ventilation in response to acute hypercapnia facilitates carbon dioxide removal and in this way maintains the acid-base balance.

Recent studies have shown that oxidative stress and antioxidant treatment may change the ventilatory response to hypercapnia [1]. Oxidative stress developed at several disease states is a major stimulus for the cytokine induction. Serum levels of inflammatory cytokines have been reported to be increased in many respiratory diseases such as asthma, chronic obstructive pulmonary disease (COPD), sleep apnea [2, 3]. These diseases are associated with a significant increase in inspiratory resistive loading. In healthy humans and animals strenuous resistive breathing also induces elevation of the plasma level of cytokines [4]. On the other hand, resistive breathing has an influence on the central chemoreception by decreasing the ventilatory response to hypercapnic stimulation [5]. Little is known about the mechanisms of this influence. We speculated that pro-inflammatory cytokines induced by oxidative stress during resistive breathing may get over the blood-brain barrier; thus increasing the level of cytokines in cerebrospinal fluid and modulating the central chemoreceptor control of breathing.

Therefore, the aim of the present study was to examine the hypothesis that the elevation of a proinflammatory cytokine in cerebrospinal fluid might modulate the ventilatory response to carbon dioxide. For this purpose, intracerebroventricular microinjections of interleukin-1 $\beta$ (IL-1 $\beta$ ), as one of the major pro-inflammatory cytokines, were used in normal animals during unloaded breathing.

\section{MATERIAL AND METHODS}

All animal procedures were conducted in accordance with the ethical guidelines of the European Community Council Directives 86/609/EEC. The experiments were performed on 10 tracheostomized rats (mean weight $270 \pm 10 \mathrm{~g}$ ), which were anaesthetized with urethane $\left(1000 \mathrm{mg} \mathrm{kg}^{-1}\right.$, i.p.). The level of anesthesia was sufficient to eliminate pain reflexes. Assessing corneal reflex and responses to tactile stimuli monitored the anaesthetic depth.

Animals were tracheostomized and cannulated with a respiratory flow head (AD Instruments MLT1L) which was connected to a pneumotachometer (AD Instruments ML141 Spirometer) to measure peak airflow and respiratory rate. Respiratory volume was obtained from the airflow integral. Minute ventilation was calculated from the mean tidal volume and respiratory frequency of ten respiratory cycles.

Esophageal pressure was measured in the lower third of esophagus with an air-filled latex balloon con- 
nected to a custom-made low pressure transducer. Records of the esophageal pressure inspiratory swings $\left(\mathrm{P}_{\text {Ies }}\right)$ were used as an indirect measure of the force of inspiratory muscle contractions and as a reflection of inspiratory driving pressure.

Rats were placed in a stereotaxic frame in the prone position with a head fixed in the 'flat scull' position used by Paxinos and Watson [6]. The skin and connective tissues were removed from the skull, a hole was drilled, and a cannula was placed into a lateral ventricle using the following stereotaxic coordinats: $0.8 \mathrm{~mm}$ posterior to bregma, $1.5 \mathrm{~mm}$ lateral from the midline, and $3.7 \mathrm{~mm}$ below the surface of the scull.

The hypercapnic ventilatory response was measured using a rebreathing technique before and after $10 \mu \mathrm{l}$ intracerebroventricular injection of either saline (placebo) or human recombinant IL-1 $\beta(0.5 \mu \mathrm{g} / \mathrm{rat})$. The hyperoxic hypercapnic rebreathing was carried out with a modified rebreathing method of Read [7]. For the hypercapnic rebreathing test, animals breathed from a bag with a gas mixture of $60 \% \mathrm{O}_{2}$, $7 \% \mathrm{CO}_{2}$, balanced with $\mathrm{N}_{2}$. The end-tidal partial pressure of carbon dioxide $\left(\mathrm{P}_{\mathrm{ET}} \mathrm{CO}_{2}\right)$ was analyzed with a rapidly responding quadruple mass spectrometer (model MC-100, Institute of Analytic Instrumentmaking, Russian Academy of Sciences), which was calibrated immediately before and after use with known gas mixtures carried onboard. A gradual rise in the end-tidal $\mathrm{CO}_{2}$ concentration was recorded for 4 min and was monitored on the breath-to-breath basis. At the end of the rebreathing period, the end-tidal $\mathrm{O}_{2}$ was on average more than $190 \mathrm{mmHg}$, eliminating the possibility of any hypoxic stimulus. The responses of tidal volume $\left(\mathrm{V}_{\mathrm{T}}\right)$, frequency $(\mathrm{f})$, mean inspiratory flow $(\mathrm{V})$, minute ventilation $\left(\mathrm{V}_{\mathrm{E}}\right)$ and esophageal pressure $\left(\mathrm{P}_{\text {Ies }}\right)$ to increases in $\mathrm{P}_{\mathrm{ET}} \mathrm{CO}_{2}$ were analyzed by linear regression. The respective slopes of $\Delta \mathrm{V}_{\mathrm{E}} / \Delta \mathrm{P}_{\mathrm{ET}} \mathrm{CO}_{2}, \Delta \mathrm{V} / \Delta \mathrm{P}_{\mathrm{ET}} \mathrm{CO}_{2}$ and $\Delta \mathrm{P}_{\text {Ies }} / \Delta \mathrm{P}_{\mathrm{ET}} \mathrm{CO}_{2}$ were obtained at $\mathrm{P}_{\mathrm{ET}} \mathrm{CO}_{2}$ between 40 and $80 \mathrm{mmHg}$. Mean inspiratory flow was the tidal volume divided by the inspiratory time.

Data were expressed as means \pm SE. Statistical comparisons between measurements before and after intracerebroventricular injections were performed using dispersion analysis. Differences were considered significant at a value of $\mathrm{P}<0.05$.

\section{RESULTS}

Intracerebroventricular injections of IL-1 $\beta$ evoked changes in resting breathing pattern. IL-1 $\beta$ significantly increased minute ventilation and the mean inspiratory flow (Table 1). Tidal volume and esophageal pressure also showed a tendency to increase, but this trend did not achieve significance. Respiratory frequency and $\mathrm{P}_{\mathrm{ET}} \mathrm{CO}_{2}$ remained unchanged in IL- $1 \beta$-treated rats. In contrast, injection of saline had not influence on breathing pattern.

In the present study, intracerebroventricular administration of IL-1 $\beta$ evoked changes in the hypercapnic responses. There were significant relationships between minute ventilation, tidal volume, mean inspiratory flow, and esophageal pressure, on the one hand, and a rising $\mathrm{P}_{\mathrm{ET}} \mathrm{CO}_{2}$, on the other, both before and after injections of either IL-1 $\beta$ or saline. Respiratory rate, which remained unchanged after IL-1 $\beta$, did not correlate with a gradual rise of $\mathrm{P}_{\mathrm{ET}} \mathrm{CO}_{2}$ (Table 2). Fig. 1 demonstrates that these relationships, except the one for the esophageal pressure (Panel C), were appreciably less steep after IL-1 $\beta$ injection. No such decreases

Table 1. Breathing pattern before and after intracerebroventricular injections of IL-1 $\beta$.

\begin{tabular}{lrc}
\hline Variables & \multicolumn{2}{c}{ Interleukin-1 $\beta$} \\
& Before & After \\
\hline Minute ventilation, $\mathrm{ml} / \mathrm{min}$ & $103.0 \pm 5.3$ & $126.0 \pm 3.8^{* *}$ \\
Tidal volume, $\mathrm{ml}$ & $1.0 \pm 0.1$ & $1.2 \pm 0.1$ \\
Respiratory frequency, breaths/min & $112.0 \pm 7.0$ & $113.0 \pm 7.0$ \\
Mean inspiratory flow, $\mathrm{ml} / \mathrm{s}$ & $3.7 \pm 0.3$ & $4.4 \pm 0.1^{*}$ \\
Eesophageal pressure, $\mathrm{mmH} \mathrm{H}_{2} \mathrm{O}$ & $1.6 \pm 0.4$ & $2.5 \pm 0.5$ \\
End-tidal $\mathrm{CO}_{2}, \mathrm{mmHg}$ & $34.0 \pm 3.0$ & $30.0 \pm 3.0$ \\
\hline
\end{tabular}

Values are means \pm SE. $* \mathrm{P}<0.05$ and $* * \mathrm{P}<0.01$ for the comparison before and IL- $1 \beta$ treatment.

Table 2. Ventilatory and breathing pattern responses to hypercapnia before and after intracerebroventricular injections of IL-1 $\beta$.

\begin{tabular}{lll}
\hline Parameters & \multicolumn{2}{c}{ Interleukin-1 $\beta$} \\
& Before & After \\
\hline Slop of ventilatory response, $\mathrm{ml} / \mathrm{min} / \mathrm{mmHg}$ & $5.5 \pm 0.5$ & $2.9 \pm 0.3^{* *}$ \\
Slop of tidal volume response, $\mathrm{ml} / \mathrm{mmHg}$ & $0.05 \pm 0.005$ & $0.03 \pm 0.003^{*}$ \\
Slop of mean inspiratory flow response, $\mathrm{ml} / \mathrm{s} / \mathrm{mmHg}$ & $0.2 \pm 0.02$ & $0.1 \pm 0.01^{* *}$ \\
Slop of esophageal pressure response, $\mathrm{mmH}_{2} \mathrm{O} / \mathrm{mmHg}$ & $0.1 \pm 0.02$ & $0.1 \pm 0.04$
\end{tabular}

Values are means $\pm \mathrm{SE} . * \mathrm{P}<0.05$ and $* * \mathrm{P}<0.01$ for the comparison before and IL-1 $\beta$ treatment. 

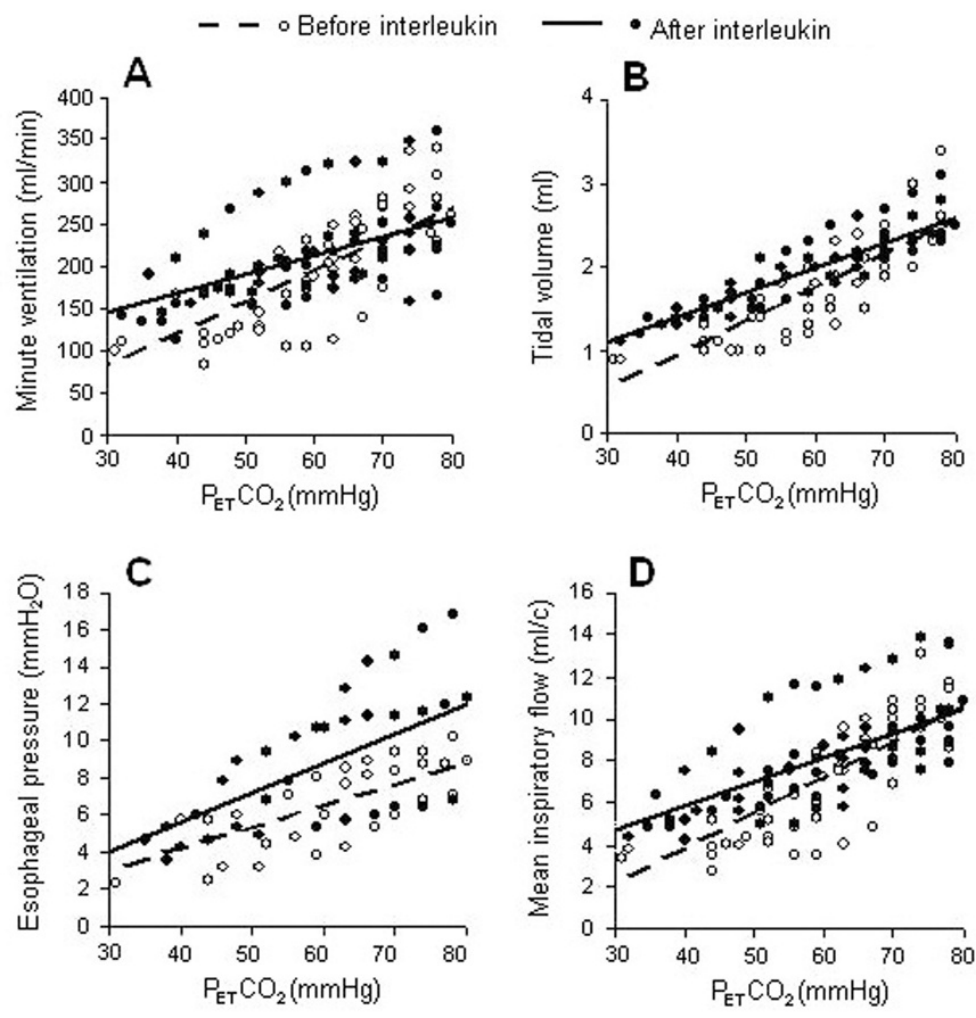

Fig. 1. Regression lines describing the relationships between minute ventilation (A), tidal volume (B), esophageal pressure (C), and mean inspiratory flow (D), on the one side, and progressive hypercapnia, on the other side, before (dashed lines) and after (solid lines) intracerebroventricular administration of IL-1 $\beta$.
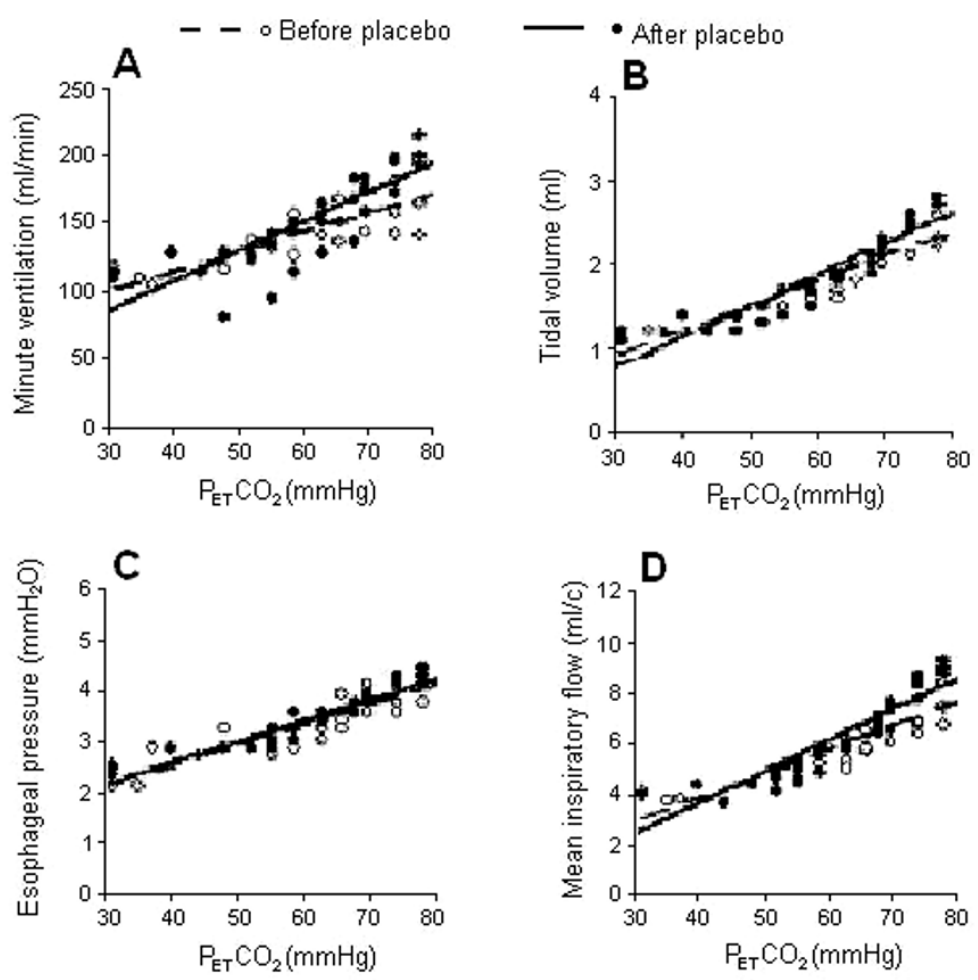

Fig. 2. Regression lines describing the relationships between minute ventilation (A), tidal volume (B), esophageal pressure $(C)$, and mean inspiratory flow (D), on the one side, and progressive hypercapnia, on the other side, before (dashed lines) and after (solid lines) intracerebroventricular administration of saline.

during hypercapnia were detected after placebo injections (Fig. 2).

\section{Discussion}

The present study demonstrates that an increased level of IL-1 $\beta$ in cerebrospinal fluid modulated the central chemoreceptor control of breathing in that it de- creased the chemoreflex sensitivity to $\mathrm{CO}_{2}$. It has been shown that endogenously produced tumor necrosis factor- $\alpha$ (TNF- $\alpha$ ) blunts the ventilatory response to hypercapnia [8]. These data allow supposing that a high level of expression of proinflammatory cytokines, such as TNF- $\alpha$ and IL- $1 \beta$, observed after strenuous respiratory muscle contraction [4] may be the cause of decreasing the central chemoreflex sensi- 
tivity in resistive load breathing. According to our data, the decrease in the hypercapnic ventilatory response resulted from a lower volume component of ventilation, with no major contribution of respiratory rate. In addition, the present study shows that IL-1 $\beta$ influences the resting breathing pattern in normal animals, as administration of the cytokine increased minute ventilation and mean inspiratory flow. These data indicate that IL- $1 \beta$ influences the central respiratory pattern generator that controls the tidal but not frequency breathing.

Not only does central but also systemic administration of IL-1 $\beta$ increase ventilation. Intravenous injections of IL-1 $\beta$ and endotoxin, which leads to pro-inflammatory cytokine release, stimulate the respiratory controller $[9,10]$. Interestingly, in the present study IL-1 $\beta$ had different central effects on the resting and hypercapnia-stimulated breathings. At rest, IL-1 $\beta$ increased ventilation. In contrast, the hypercapnic-stimulated breathing was depressed by it, as evidenced by decreases in the ventilatory response slopes. It is possible that distinct neural pathways may underlie these responses. Resent studies have shown that IL-1 $\beta$ receptors are abundantly expressed in the brain stem regions involved in respiratory control. We believe that the central effect of IL-1 $\beta$ on the chemoreflex sensitivity could be the result of inhibition of neurons sensitive to $\mathrm{CO}_{2}$. This could be either a direct effect on IL-1 $\beta$ receptors or indirectly through the NO- and eicosanoid-dependent mechanisms that modulate IL-1 $\beta$ ventilatory effects [9].

In conclusion, we believe we have shown that exogenously elevated IL-1 $\beta$ in cerebrospinal fluid intensifies resting ventilation and weakens the hypercapnic ventilatory response, which suggests the participation of proinflammatory cytokines in the mechanisms of central control of breathing pattern and central $\mathrm{CO}_{2}$ chemoreception.

Acknowledgments: The study was supported by the Russian Foundation for Basic Research (RFBR) grant No. 09-0401662.

Conflicts of interests: The authors declare no conflicts of interest in relation to this article.

\section{REFERENCES}

1. Zakynthinos S, Katsaounou P, Karatza M-H, Roussos C, Vassilakopoulos T. Antioxidants increase the ventilatory response to hyperocxic hypercapnia. Am J Respir Crit Care Med 2007; 175: 62-8.

2. Vernooy JH, Kucukaycan M, Jacobs JA, Chavannes NH, Buurman WA, Dentener MA, Wouters EF. Local and systemic inflammation in patients with chronic obstructive pulmonary disease: soluble tumor necrosis factor receptors are increased in sputum. Am J Respir Crit Care Med 2002; 166: 1218-24.

3. Vgontzas AN, Paranicolaou DA, Bixler EO, Hopper K, Lotsikas A, Lin HM, Kales A, Chrousos GP. Sleep apnoea and daytime sleepiness and fatigue: relation to visceral obesity, insulin resistance and hypercytokinemia. J Clin Endocrinol Metab 2000; 85: 1151-8.

4. Vassilakopoulos T, Roussos C, Zakynthinos S. The immune response to resistive breathing. Eur Respir J 2004; 1033-43.

5. Mador JM, Tobin MJ. The effect of inspiratory muscle fatigue on breathing pattern and ventilatory response to $\mathrm{CO}_{2}$. J Physiol 1992; 455: 17-32.

6. Paxinos $G$, Watson $C$. The rat brain in stereotaxic coordinates. London, Academic Press, 1982.

7. Read DJ. A clinical method for assessing the ventilatory response to carbon dioxide. Australas Ann Med 1967; 16: 20-2.

8. Gosselin LE, Barkley JE, Spencer MJ, McCormick KM, Farkas GA. Ventilatory dysfunction in $\mathrm{mdx}$ mice: Impact of tumor necrosis factor-alpha deletion. Muscle Nerve 2003; 28: 336-43.

9. Graff GR, Gosal D. Cardiorespiratory responses to interleukin-1 $\beta$ in adult rats: role of nitric oxide, eicosanoids and glucocorticoids. Arch Physiol Biochem 1999: 107: $97-$ 112.

10. Preas HL, Jubran A, Vandivier RW, Reda D, Godin PJ, Banks SM, Tobin MJ, Suffredini AF. Effect of endotoxin on ventilation and breath variability: role of cyclooxygenase pathway. Am J Respir Crit Care Med 2001; 164: 6206.

Address for correspondence:

Nina P. Aleksandrova

6, Makarova Nab.

St. Petersburg, 199034

Russia

E-mail: n_aleks@yahoo.com 